\title{
Current Situation Analysis and Suggestions for Professional Development of Bilingual Teachers of 0-3-Year-Old Children Taking Shenyang for example
}

\author{
Lina Zhang Yu Yuan \\ Teachers' College Shenyang University \\ Shenyang, China \\ Teachers' College Shenyang University \\ Shenyang, China
}

Keywords: 0-3-year-old children, professional development, bilingual teachers

\begin{abstract}
With education reform in China keeps advancing, the development of pre-school education is also receiving more and more attention and support on the national and local levels. With kindergarten work carrying out in full swing, another group of education institutions - early education institutions for 0-3-year-old children also come into being and receive thriving development. Among these education institutions, those featuring English teaching are the most popular among parents. It is also known that teacher quality is one of the important components in the field of education. On the basis of literature review, this paper analyzes the professional development situation of teachers and provides suggestions based on the early education development and teacher quality of Shenyang.
\end{abstract}

\section{Introduction}

In recent years, the society has paid more attention to child care services and pre-school education. In this year's report on the work of the government, the Prime Minister proposed to provide more resources to pre-school education through multiple channels and strengthen supervision during the whole process of child care work. At the 13th National People's Congress (NPC), Chen Baosheng, China's Minister of Education, gave an encouraging answer to Chinese and foreign journalists' questions about "making every child enjoy fair and quality education". He said that the priority is to launch legislation on pre-school education, which is also in the development plan of the next stage. Against this backdrop with preferential policies, more and more kindergartens are seeking further improvement and development gradually, making breakthroughs and advancements in bilingual education. However, even with supportive policies for pre-school education, the development of early education for 0-3-year-old children is still being left behind with multiple problems awaits resolution, as much as injured soldiers struggling on the battlefield. With bilingual education rapidly developing and household income steadily increasing, many "international" bilingual education institutions for 0-3-year-old children spring up everywhere. Among the many factors influencing course quality, teacher quality shall be taken into careful consideration. This paper aims to explore the professional development of English teachers at bilingual early education institutions for 0-3-year-old children.

\section{Current situation of bilingual early education institutions for 0-3-year-old children}

Since early education for children aged 0-3 years is not originated from China, many early education institutions in China adopt early education experience from Europe and America for reference and introduce foreign courses and teaching methods, such as the Montessori Method of Education (abbreviated the Montessori Method) and Orff Music. Currently there are mainly two kinds of English early education institutions in China, one is a specialized English early education institution, which focuses on bilingual teaching and is equipped with English teachers and Chinese teaching assistants with the teaching objects aged from several months to several years old. The 
other kind of early education institution is for children aged 0-3 years, which offers courses of different subjects, including English courses. ${ }^{[1]}$ In short, the former features bilingual teaching, conducting all teaching activities in English, while the latter includes English into the curriculum as a subject. The former aims to foster bilinguals, while the latter intends to cultivate foreign language learners. The former mainly set up in the first - and second-tier cities, with few of them in small or medium-sized cities. ${ }^{[2]}$ These institutions normally requires high tuition fees, signifying high consumption in the field of education investment. As these institutions going commercial at a fast speed, there exist such issues as lack of supervision from the education department, irrational profit-seeking behavior, management disorder, lack of tuition fee standard, teachers of varying quality and lack of trainings in line with the rules of education and teaching.

\section{Types of early education institutions for 0-3-year-old children in Shenyang 3.1 Categorized based on course types}

Within this category, there are: early education institutions adopting the Montessori Method, such as Oriental BabyCare; international early education institutions adopting the same curriculum system as western countries which were introduced from European countries, America and Australia, such as Gymboree, MyGym and KindyRoo; early education institutions focusing on whole brain development, such as FasTrackKids; local early education institutions using self-developed education mechanisms in Chinese mainland; and early education institutions using self-developed education mechanisms in Hong Kong, Macao and Taiwan.

\subsection{Categorized based on scales}

Within this category, there are: early education institutions under public kindergartens; chain early education institutions; and private early education institutions. Among these types of early education institutions, the private ones vary from each other in terms of scale, featuring different operational and management levels.

\subsection{Categorized based on language environment}

Early education institutions in Shenyang are divided into two types, one giving courses in Chinese only and the other in both English and Chinese.

\section{Existing problems in professional development of teachers at bilingual early education institutions for 0-3-year-old children in Shenyang}

Early education for young children is an important organic component in the early stage of preschool education. And teacher quality exerts an important and significant impact on any educational development. It has been 15 years since early education for 0-3-year-old children emerged in Chinese mainland. Bilingual early education has a history of 10 years or so in Shenyang, accounted as a new and promising cause in the field of education. However, the faculty construction has not yet reached systematic and professional standards, and the professional quality of English instructors is even more worrying. At present, there are many problems in terms of teachers' professional development in most early education institutions, which are listed as follows:

\subsection{Kindergarten teachers work as English instructors at early education institutions}

Due to their rapid development, early education institutions in China are having growing demand in terms of the quantity of teachers as well as the quality of teachers. A teacher at an early education institution may not only master the physical and mental developmental characteristics of young children, but also be able to speak fluent English. At the same time, pre-school education do not receive enough attention compared with secondary vocational schools and higher institutions or primary and secondary schools in China, and the social status and income of kindergarten teachers are at a relatively low level. Against this background, many kindergarten teachers turn themselves into early education teachers. They become English instructors of bilingual courses after teaching 
Chinese and being bilingual course assistants for a certain period and having trainings that are not strict or professional enough carried out by other senior teachers. Through this kind of "fast-food-alike" education service, the problem of this kind of teachers will gradually emerge, for example: firstly, some teachers may have difficulty in pronouncing correctly the English words at class and may even not be able to fully understand and completely conveys the contents in the teaching plan due to their lack of professional English learning and training, causing parents misunderstand teachers' instructions and failing to create to create an ideal language environment for children and parents. In this way, it doesn't make much sense for early education institutions to set up bilingual courses for it will become a mere formality; secondly, kindergarten teachers' professional knowledge focuses on pre-school children aged 3-6 years, but not young children aged 0-3 years.

\subsection{English-major graduates and English teachers work as English instructors at early education institutions}

With English education institutions developing for so many years, the number of such institutions continues to keep increasing. Many young people who have graduated from English major have also seen the promising prospects of bilingual early education institutions for 0 -3-year-old young children and entered this relatively well-paid area with their English competence. Unlike those teachers who used to work at kindergartens, they can speak English. However, they know little about the physical and mental developmental characteristics of children aged 0-3 years. Due to their lack of such understanding of children, they may not be able to provide suitable assistance and suggestions to parents in a timely manner. For example, why a child's crying and whether it is out of physical or psychological need. Before they become English instructors, these teachers worked as teacher assistants for bilingual classes for a certain period and they learn directly from the current English instructors, who varies from each other in terms of professional capabilities. Therefore, the professional skills they acquired may not be systemic or correct.

\subsection{The career growth atmosphere for English instructors isn't so friendly and there is huge mobility of staff in the industry}

Speaking of in-service professional development of teachers, we should pay attention to the growth environment, work conditions, developmental needs and salary and benefits of teachers, especially the development and needs of teachers with great performance. The problems encountered by teachers in their professional development include:

\subsubsection{Poor profession recognition}

Although teachers working at early education institutions are called "teachers", many of them may have difficulty in recognizing the profession correctly. For the reason that these teachers most frequently get in touch with newborns and young children less than 3 year old, they need to care for the children so much that in the case of parents having no or little experience and having trouble in taking care of their children, teachers may need to assist parents in such works as changing diapers or making milk powder. In such cases, some teachers may look at themselves as "nurses" taking care of babies Even though they themselves can give bilingual classes in fluent English. They may not be able to accept the attitudes of some parents and thus affecting teachers' confidence.

\subsubsection{Low salary}

Although early education institutions tend to provide higher salary to teachers than kindergartens, teachers can only obtain a small proportion of the class fee, with the minimum being one tenth of the class fee while the maximum no more than one quarter. In this way, teachers can only increase their income by giving a large number of lessons. The intensity of giving twenty or thirty classes a week makes teachers feel psychologically unbalanced, and they think their value and efforts aren't well reflected. As a result, many teachers turn to other jobs after working at early education institutions under great intensity.

\subsubsection{Few further training opportunities}

When teachers just enter the industry of early education, they tend to be full of confidence and hope, wanting to make contributions to the industry while having themselves recognized. However, after 
they work for a period of time, teachers may find it hard for themselves to be upgraded to a higher level in terms of professional development and thus loosing confidence to the industry. Bilingual early education institutions shall provide more opportunities to teachers for further training, but they are faced with such problems as: firstly, some institutions, with a heavy workload and small amount of staff, do not have time to arrange effective trainings or send teachers for outside-campus trainings; secondly, teacher training may cost a lot and some institutions may not want to spend this sum of money on teachers who already can give lessons due to their scales or limitations of operational cost. ${ }^{[3]}$ This is why the comprehensive quality of many teachers at early education institutions for 0-3-year-old children cannot be improved.

\subsection{Insufficient governmental investment and lack of supervision}

In recent years, the government has repeatedly emphasized the importance of pre-school education in some important meetings. However, there has been no significant increase in financial input. According to statistics, from 1998 to 2004, the government's financial investment of education funds for children accounted for $0.04 \%$ to $0.05 \%$ of GDP. These funds are for education institutions for children aged 3-6 years. For early education institutions for children aged 0-3 years, the state and government has basically invested nothing, and seldom participate in the management and supervision. ${ }^{[4]}$ Related education departments also failed to effectively supervise early education institutions, resulting in varying quality of teachers, different charging standards, and generally higher prices in the industry of early education institution for children aged $0-3$ years. ${ }^{[1]}$

\section{Suggestions on the cultivation of English instructors at bilingual early education for 0-3-year-old children}

\subsection{Improve pre-school English-major teacher training}

Although when training pre-school majors, secondary vocational schools and higher institutions focus on the cultivation of teachers at kindergartens for 3-6-year-old children while set up some specified pre-school professional English courses, generally English professional training does not reach the standard of being systemic and specialized. After such training for a few years, teachers do not have such English levels to independently give English lessons. Therefore, the author suggests that a professional English course shall be set provided by secondary vocational schools and higher institutions for the cultivation of pre-school profession talents, providing opportunities to students to learn a foreign language in the actual sense while they are at school.

\subsection{Strengthen supervision from related departments}

As a part of the emerging educational cause, bilingual early education institutions for 0-3-year-old children have many deficiencies and problems in its management mode, price orientation, service objects and teacher training. If these problems cannot be sorted out and corrected in time, more and more problems will emerged under this circumstance. Even though these early education institutions are highly commercial, they undoubtedly provide a good platform to parents who don't acquired much child care knowledge to understand how children grow up in a healthy way and to create a domestic education atmosphere as good as possible. Therefore, related education departments shall strengthen supervision and management to guarantee the healthy development of early education institutions for children aged 0-3 years.

\subsection{Focus on in-service training of English instructors at bilingual early education institutions for 0-3-year-old children}

5.3.1 What new teachers need and desire most at the early stage of entering an early education institution is systematic and professional enterprise training and professional training. ${ }^{[5]}$ The teaching department of bilingual early education institutions for 0-3-year-old children should have experienced "senior teachers" sum up their teaching experience and work out a professional training system of English instructors in line with the early education teaching theory.

5.3.2 Progress should be made in terms of learning. Such bilingual early education institutions 
should arrange teachers to countries or regions with a matured system of early education for further learning and have their curriculum updated in a timely manner, so as to make their own innovations, carry out a "bilingual early education" system of their own features, and cultivate a group of teachers who are professional, experienced, endured and can do research.

\section{Conclusion}

The professional development of English instructors at bilingual early education institutions for children aged 0-3 years is crucial for the development of early childhood education in China, not only for the personal vocational development of teachers, but also for the benefit of hundreds of millions of families. On the basis of literature review, this paper explores the professional development of English instructors of 0-3-year-old children and puts forward suggestions on the cultivation of English instructors of 0-3-year-old children, which include: improve pre-school English-major teacher training; focus on in-service training of English instructors at bilingual early education institutions for 0-3-year-old children; and strengthen supervision from related departments. This paper is only on the theoretical level to analyze and study the professional development of bilingual teachers for children aged 0-3 years. The research results are lack of exploration and research on the practical level, and the discussion on the suggestions on the training of English instructors for children aged 0-3 years is not sufficient enough.

\section{References}

[1] Wang Yinghui. Preliminary Thoughts on Teachers' Professional Development in early education institutions for 0-3-year-old Infants. [J]. Education and Teaching Research, 2013, 8, 0111, 03

[2] Ding Qing, Meng Fanxu. Misunderstanding of English Early Eduction Institutions and "out of " Sugessstions [J]. Journal of Education College Jilin, 2015,09,31

[3] Guo Liping, Li lin. The Necessity and Feasibility of Infant English Education---To Investigate and Analyze Kindergarten Principals in Shanghai [J]. Shanghai Education and Research, 2003(09).

[4] Chen Lixia. Exploratin to the Construction of Teaching Staff in Early Education Institution [J]. China's National Education,2011, (6).

[5] Wang Yinghui. Current Situation and Suggestions for Post-employment Faculty Training in 0-3-year-old Infant Early Education Institutions [J]. Journal of Jixi University, 2012, (6).

[6] Ni Jianfa. Current Situation and Research into the Approaches to Construct Preschool Education Teaching Staff, Journal of WenzhouUniversity, 2012, (2). 